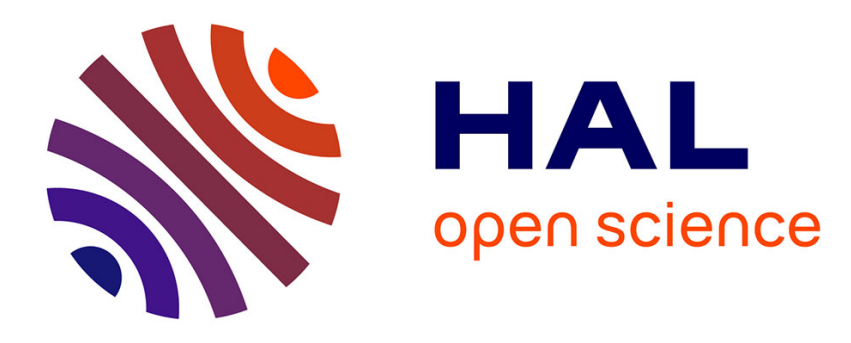

\title{
Carbon-carbon composites : oxidation behavior and coatings protection
}

\author{
M. Bacos
}

\section{To cite this version:}

M. Bacos. Carbon-carbon composites: oxidation behavior and coatings protection. Journal de Physique IV Proceedings, 1993, 03 (C7), pp.C7-1895-C7-1903. 10.1051/jp4:19937303 ～jpa-00251947

\section{HAL Id: jpa-00251947 https://hal.science/jpa-00251947}

Submitted on 1 Jan 1993

HAL is a multi-disciplinary open access archive for the deposit and dissemination of scientific research documents, whether they are published or not. The documents may come from teaching and research institutions in France or abroad, or from public or private research centers.
L'archive ouverte pluridisciplinaire HAL, est destinée au dépôt et à la diffusion de documents scientifiques de niveau recherche, publiés ou non, émanant des établissements d'enseignement et de recherche français ou étrangers, des laboratoires publics ou privés. 


\title{
Carbon-carbon composites: oxidation behavior and coatings protection
}

\author{
M.P. BACOS \\ Office National d'Etudes et de Recherches Aérospatiales, Direction des Matériaux, BP. 72, 92322 Châtillon \\ cedex, France
}

\begin{abstract}
Based on their good mechanical performances, potential uses of structural carbon materials have been identified in high temperature applications. Many applications require extended periods ranging from a few hours (at high temperature) to a few thousands of hours (at low temperature) in oxidizing environments where unprotected carboncarbon composites deteriorate rapidly. Therefore numerous investigations have been conducted in an attempt to protect carbon-carbon composites against oxidation. The main protection mechanism relies on the use of a barrier against oxygen diffusion. The problem, when applying this concept, is the thermal mismatch between coating and carbon substrate which results in cracking of the coatings. Thereby, oxygen diffuses through the cracks, causes oxidation of the underlying carbon which leads to the spallation of the coatings. Therefore other approaches have been developed including : (1) intermediate layers, (2) inhibited matrices and (3) fiber protections: The purpose of this work is to examine the oxidation of carbon-carbon composites and to evaluate the inherent limitations of the various current coatings. Recently due to these limitations, composite coatings have been studied. Morever, a new concept has been developed. It is proposed that the introduction of an inert gas into the boundary layer at the carbon composite surface will provide some protection.
\end{abstract}

\section{1-Introduction}

Carbon-carbon $(\mathrm{C} / \mathrm{C})$ composites are increasingly being considered for aerospace applications. In composite materials, the fibers impart strength, stiffness and fatigue resistance, while the carbon matrix holds the fibers together. A synergistic effect also exists between the fiber and the carbon matrix which results in high fracture toughness and wear resistance. But the most attractive properties of carbon-carbon composites are their high specific strength and modulus [1].

Based on their good mechanical performances, potential uses of structural carbon materials have been identified in future manned hypersonic vehicles (Hermes, Sänger, Hotol) and in other aircraft applications. However, most of these applications involve extended time periods in oxidizing environments. Unfortunately, carbon reacis rapidly with oxygen at temperatures as low as $500^{\circ} \mathrm{C}$ and the composites are subject to oxidation degradation. Less is known about the effects of oxidation on the properties of $\mathrm{C} / \mathrm{C}$ composites, because they vary with the oxidation mechanisms and the microstructural features of the materials [2,3]. But it is well known that oxidation degrades quickly the properties of carbon materials [4-7]. Therefore, numerous investigations have been conducted in an attempt to protect carbon based composites against oxidation.

The first protection mechanisms are based on a macroscopic concept with the use of a barrier against oxygen diffusion at high temperature. The main problem, when applying this concept, is the thermal mismatch between coating and carbon substrate which results in cracking of the coating. Thus, other approaches have been developed including : (1) intermediate layers, (2) inhibited matrices and (3) fiber protections.

The purpose of this work is to examine the oxidation of $\mathrm{C} / \mathrm{C}$ composites and to evaluate the inherent limitations of the various current coatings. Recently due to these limitations, composite coatings have been studied. Morever, a new concept has been developed. It is proposed that the introduction of an inert gas into the boundary layer at the carbon composite surface will provide some protection.

For this discussion, we assume that good mechanical properties are preserved for a mass loss below $3 \%$, and we define short, medium and long-term applications according to the time (15 minutes, 15 hours and 100 hours respectively) needed to reach this mass loss. 


\section{2-Carbon-carbon composites oxidation}

Carbon-carbon materials can be made in a wide variety of fiber structures from one-directional (1D) to multidirectional $(\mathrm{n} D)$ reinforcement using tows, tapes and cloths. Carbon fibers are produced from three precursor materials : polyacrilonitrile (PAN), rayon and petroleum pitch. Addition of a matrix to the carbon fibers is achieved through the carbonization of an organic precursor or by the deposition of pyrolytic carbon $[1,8]$.

As a result of this diversity, the mechanical properties of the $\mathrm{C} / \mathrm{C}$ composites can be tailored to suit specific tasks. But in return, due to this complexity of microstructure, no fundamental understanding of oxidation kinetics of the $\mathrm{C} / \mathrm{C}$ composites exists.

In fact, oxidation involves the following steps shown schematically in figure 1 [9] :

1- gas phase diffusion across the boundary layer : oxygen has to diffuse through the gaseous boundary layer at the surface.

2- gas diffusion through cracks in the composite.

3- reaction between carbon and oxygen to form oxidation products.

The diffusion steps also apply to gaseous reaction products as carbon monoxide and carbon dioxide.

According to the pressure and temperature conditions, the overall reaction rate can be limited by any of the steps listed above. The rate limiting step is the one that has the lowest rate. Generally, at low temperature, the gaseous species diffusion rate is faster than the carbon/oxygen reaction kinetics. Carbon degradation occurs within the material located preferentially either in the fiber reinforcement or in the carbon matrix according to their respective reactivity. At high temperature, the slowest step being the oxygen diffusion through the outer boundary layer, the degradation is strictly located at the surface of the $\mathrm{C} / \mathrm{C}$ material and the material bulk remains untouched.

Consequently, owing to the reactivities of the different carbon structure and the pore structure of the materials, the oxidation behavior of $\mathrm{C} / \mathrm{C}$ composites can differ from one to another. Morever, for the same $\mathrm{C} / \mathrm{C}$ composite, the degradation and the residual mechanical properties will be different according to the limiting step of oxidation.

For instance, for the following $2 \mathrm{D} \mathrm{C/C}$ composite (ex-PAN fiber and ex-phenolic resin matrix-figure 2), the total porosity is equal to $13 \%$ of the total volume. The morphological analysis of this $2 \mathrm{D}$ bare composite points out the existence of two connected pore families. The first contributes mainly to mass transport. The second provides a high specific area, and is the core of the chemical reactions. The transverse cracks and the fiber/matrix debondings belong to the first family of pores, the pores located within the bundles belong to the second family.

During oxidation, as it is shown in figure 3 , the matrix degradation is more important than the fiber oxidation leading to the formation of large holes in the matrix.

As predicted above, at low temperature the oxidation occurs within the bulk of material. Gasification appears to lead progressively to the formation of crevices and pores in the matrix, followed by the propagation of longitudinal channels along the bundles, leaving finally a porous skeleton of the original structure (figure 3 ). At this stage of the oxidation, only the fiber reinforcement remains. Gasification occurs more rapidly at the exposed ends of the fibers, due to the high density of active sites in this area, leading to blunt-pointed fibers.

At high temperature only the first layers of the material are concerned, the bulk being untouched (figure 4).

In the example of figure 5 showing a $3 \mathrm{D} C / \mathrm{C}$ composite (ex-PAN fibers and ex-pitch matrix), the crack network and the total porosity $(8 \%)$ are very different. Bundle/matrix debondings, bundle/orthogonal bundle debondings and cracks in the matrix form the main part of the porosity. Some pores of small diameter are also located within the bundles. Therefore during oxidation there is an increase of these matrix cracks and bundle/matrix or bundle/bundle debondings followed by the opening of transverse cracks within the z-direction bundles (figure 6).

Therefore, these two examples point out that the forecast of the oxidation behavior of a $\mathrm{C} / \mathrm{C}$ composite needs the knowledge of the carbon reactivities, of the porous texture and of the transport of the gaseous species within the material. However, from the analysis of the different steps of the oxidation of a $\mathrm{C} / \mathrm{C}$ composite, as described in figure 1 , it is obvious that the first approach to protect the material is the use of a coating which prevents oxygen to reach the carbon surface.

\section{3-Coatings}

\section{Oxygen barrier laver}

In the presence of a protective coating on the surface, the oxidation of a substrate involves the following steps (figure 1) [9] :

1- gas phase diffusion across the boundary layer : oxygen has to diffuse through across the boundary layer at the surface.

2-gas diffusion through cracks in the coating : if the coating is cracked, the oxygen can diffuse through the cracks to the substrate/coating interface. The diffusion coefficient depends on the crack width. For large cracks, the diffusion coefficient is the same as the bulk gas diffusion coefficient. However, for small cracks, where the mean free path of the gas molecules is of the same order as the crack size, the gas molecules collide with the walls. This reduces the effective diffusion coefficient, and transport occurs by a process called Knudsen diffusion. 
3-condensed phase diffusion : even if the coating is crack-free, oxygen can diffuse through it to oxidize the substrate. The transport mechanism depends on the defect structure of the coating.

4- gas diffusion through cracks in the composite.

5- reaction between carbon and oxygen to form oxidation products.

Desired properties for the coatings on $\mathrm{C} / \mathrm{C}$ composites are thermal expansion compatibility to minimize cracks, low oxygen and carbon diffusion, low vapor pressure, chemical compatibility with carbon, erosion, wear and impact resistance. The most important criterion is a good adequation between the thermal expansion coefficients of the coating and of the composite. Figure 7 compares the thermal expansion coefficients of refractory materials with the expansion of graphite or high performance carbon fiber.

The most suitable ceramics are some oxides (as silica) and silicon carbide or silicon nitride. But in spite of these good thermal expansion compatibilities, it is difficult to form coatings without cracks. Indeed at temperatures below the temperature of the coating application, $\left(T<1250^{\circ} \mathrm{C}\right.$ ) (figure 8 , domain I), tension-induced coating cracks exist [10]. Therefore, at low temperature, silicon carbide (nitride) works only for short-term applications. At higher temperatures (domain II) due to the closure of the cracks and to the formation of low viscosity silica, the protective properties of this type of coating are improved and this type of protection can be used for medium-term applications. At very high temperatures or medium temperatures and low oxygen pressures (domain III, figure 8), silicon carbide does not protect anymore [11-23] because of the formation of gaseous silicon monoxide either by direct active oxidation :

$$
\begin{aligned}
& \mathrm{SiC}+\mathrm{O}_{2} \rightarrow \mathrm{SiO}+\mathrm{CO} \\
& \mathrm{Si}_{3} \mathrm{~N}_{4}+3 / 2 \mathrm{O}_{2} \rightarrow 3 \mathrm{SiO}+2 \mathrm{~N}_{2}
\end{aligned}
$$

or by reaction between silica and silicon carbide (or nitride) :

- $\mathrm{SiC} / \mathrm{SiO} 2$ reaction

- $\mathrm{Si}_{3} \mathrm{~N}_{4} / \mathrm{SiO}_{2}$ reaction

$$
\begin{aligned}
& \mathrm{SiC}+2 \mathrm{SiO}_{2} \rightarrow 3 \mathrm{SiO}+\mathrm{CO} \\
& \mathrm{Si}_{3} \mathrm{~N}_{4}+3 \mathrm{SiO}_{2} \rightarrow 6 \mathrm{SiO}+2 \mathrm{~N}_{2}
\end{aligned}
$$

In this domain (domain III), $\mathrm{C} / \mathrm{C}$ composites must be protected by other ceramic materials such as oxides [24-29] or metal carbides [30-32]. Noble metals [24-25, 33-36] and borate coatings have also been studied [9, 24 , 37-39].

Oxides, metal carbides and noble metals have numerous advantages but generally they have a too large thermal expansion coefficient (figure 7). Therefore, it is very difficult to apply crack-free coatings. Other limitations are generally due to fast oxygen diffusion through oxide phases (for instance $\mathrm{ZrO}_{2}, \mathrm{HfO}_{2}$ have high oxygen permeability).

In addition, oxides can be reduced by carbon (as low as $1200^{\circ} \mathrm{C}$ for silica, $1730^{\circ} \mathrm{C}$ for $\mathrm{ZrO}_{2}, 1750^{\circ} \mathrm{C}$ for $\mathrm{HfO}_{2}$ ). As a consequence, direct oxide deposit on carbon must be avoided. Oxides are generally used as the upper layer (oxygen barrier layer) in multilayer coatings.

Refractory group metals, such as iridium and ruthenium, present poor adherence to carbon materials, erosion via volatile oxidation, high cost and short supply. At present, iridium is used in multilayer coating concepts [36].

Boron oxide is an attractive compound for the protection against oxidation. The chemical compatibility of $\mathrm{B}_{2} \mathrm{O}_{3}$ with carbon, its good wetting property and its low viscosity $\left(10^{4}\right.$ to $10^{2} \mathrm{dPa}$ in the $600-1100^{\circ} \mathrm{C}$ range) allow the formation of thin protective glass films [9, 24, 37-39]. The main limitations of borate glasses are their moisture sensitivities [40] (hydrolysis under ambiant conditions) and at higher temperatures the vaporisation of boron oxide [37]. Under dry conditions, borate glass coatings can be used up to $600^{\circ} \mathrm{C}$ and $1000^{\circ} \mathrm{C}$ for long and short-term applications respectively.

Many materials are candidate to protect $\mathrm{C} / \mathrm{C}$ composites against oxidation. Unfortunately, because of thermal expansion differences and poor adherence properties, most ceramic materials do not form satisfying coatings on $\mathrm{C} / \mathrm{C}$ composites. These coatings present cracks, and therefore the oxidation occurs beneath the coating leading to its spallation. To minimize the density of cracks, transition layers have been developed. Another way to protect the composites and to limit the effects of cracks, is to use glass formers (inhibited matrix) which are able to form a mobile glass which spreads within the cracks.

\section{$\underline{\text { Transition layers }}$}

Carbide conversion layers improve surface cohesive strength. Most of the transition layers are made by a 
pack cementation process [49-50], and sometimes these layers are doped (e.g. zirconium or boron) [63]. This transition layer is often used beneath an outer CVD coating $[31,41-48]$ and this double protection is efficient up to $1000^{\circ} \mathrm{C}$ and $1600^{\circ} \mathrm{C}$ for medium and short-term applications in a dry atmosphere. Other intermediate layers such as porous CVD silicon layer [51] or graded coatings [52] have been developed but seem less efficient. Physical methods such as ion implantation (e.g. boron) have also been tested [52] in order to reduce the oxidation rate at low temperature.

\section{$\underline{\text { Inhibited matrix }}$}

The oxidation protection concept with the use of a diffusion barrier is not valid when damage probabilities are great (meteorite impact ...). For that reason a new approach has been developed by adding in the carbon precursor some glass formers which are able to spread within the cracks [48,53-57]. The components studied are mainly $\mathrm{B}_{4} \mathrm{C}, \mathrm{B}, \mathrm{CrB}_{2}, \mathrm{ZrB}_{2}, \mathrm{SiB}_{4}, \mathrm{AlB}_{12}, \mathrm{ZrH}-\mathrm{Si}, \mathrm{ZrB}_{2}-\mathrm{Si}, \mathrm{SiC}$ and phosphates. With only inhibited matrix, no protection occurs before an appreciable fraction of carbon $(30 \%)$ has been gasified. Therefore this type of protection is generally used in addition to other protection systems [31, 41, 45, 46-48]. But the addition of inhibitors can modify the mechanical properties of the composite [58]. Indeed, heat treatment of carbonized composites containing glass forming inhibitors such as boron or zirconium diboride above initial carbonisation temperature results in reduced mechanical properties [58].

\section{Coatings on fibers}

In order to protect the carbonaceous fibrous reinforcement, several coatings have been developed. Most of them have been applied by chemical vapor deposition [59-60] and by sol-gel methods [61].

\section{4-Complex systems and multilayer coatings}

In many aerospace applications, the desired properties of $C / C$ composites are thermal stability, thermal shock resistance, oxidation resistance under thermal cycling conditions in a 1 atmosphere air pressure or in a partial reduced pressure of molecular or atomic oxygen, resistance to degradation by moisture, resistance to rain erosion, high ernittance and multi-mission reliability.

In order to reach this objective, many complex systems have been developed including : coatings on fibers, inhibited matrix, transition layer, coating and outer glass sealant [62] (figure 9). Most of these oxidation protection systems contain SiC CVD coating on fibers, boron or silicon carbide in the matrix, silicon carbide converted layer, silicon carbide CVD coating and outer silica (or borosilica) glass [22, 46-48, 51, 62]. Unfortunately, these systems based on silicon carbide are not efficient beyond $1800^{\circ} \mathrm{C}$ in a dry atmosphere due to the active oxidation of silicon carbide. Moreover, in a humid atmosphere, this type of protection (which includes boron protection, as glass former in the matrix or component of the outer glass) can only work up to $1100^{\circ} \mathrm{C}$ for medium-term applications. Indeed, moisture absorption and subsequent rapid gas formation during heating lead to the spallation of the coating from the substrate [62].

Therefore in order to adjust their properties to the substrates composite coatings have been developed.

\section{5-Composite coatings}

Composite coatings have been developed using chemical vapor deposition (CVD), plasma spraying techniques or powder and polymer mixtures.

Many coatings have been realized by chemical vapor deposition such as $\mathrm{Si}_{3} \mathrm{~N}_{4}+\mathrm{TiN}$ [64-68], $\mathrm{Si}_{3} \mathrm{~N}_{4}+\mathrm{BN}$ [64,69], $\mathrm{Si}_{3} \mathrm{~N}_{4}+\mathrm{SiC}[64], \mathrm{SiC}+\mathrm{TiSi}_{2}[64,70,76], \mathrm{SiC}+\mathrm{TiC}$ [71], AIN + BN [72-73], TiB ${ }_{2}+\mathrm{TiC}$ [74], AIN + $\mathrm{Si}_{3} \mathrm{~N}_{4}$ [75], $\mathrm{ZrC}+\mathrm{BN}$ [52] et $\mathrm{HfC}+\mathrm{HfSi}_{2}[77]$. All these systems offer the promise of tailoring properties such as friction coefficient, hardness, resistance to wear and erosion or optical properties. Only $\mathrm{ZrC}+\mathrm{BN}$ and $\mathrm{HfC}+\mathrm{HfSi}_{2}$ have been developed as protective coatings for $\mathrm{C} / \mathrm{C}$ composite and are used in a multilayer protective concept [52,77].

Thermal sprayed coating of $\mathrm{HfC}$ and $\mathrm{HfB}_{2}$ composite systems [78] and low-pressure plasma deposition of SiC-reinforced $\mathrm{MoSi}_{2}[79]$ have also been studied .

Another promising approach is to use an oxide phase to cement particles of refractory materials and to form an impermeable coating [80-81]. For instance crack-free (but porous) composite coatings composed of yttria-stabilized zirconia and $\mathrm{SiC}$ whiskers have been deposited on carbon [80]. Other coatings as high melting point borate $\left(\mathrm{Ce}\left(\mathrm{BO}_{2}\right)_{3}\right)$ with $\mathrm{SiC}$ whiskers, zirconium silicate/boron oxide $\left(\mathrm{ZrSiO}_{4} / \mathrm{B}_{2} \mathrm{O}_{3}\right)$ or hafnium boride/boron oxide $\left(\mathrm{HfB}_{2} / \mathrm{B}_{2} \mathrm{O}_{3}\right)$ have been tested to protect $\mathrm{C} / \mathrm{C}$ composite [81]. But all these coatings contain boron oxide which is volatile at high temperature or low pressure and medium temperature and which is moisture sensitive. Therefore, this type of coating 
is used in a dry atmosphere up to $1200^{\circ} \mathrm{C}$ for medium-term applications.

Finally, some authors propose composite graded coatings such as mixed oxides [82]. For instance, the following system : mullite/ $75 \%$ mullite-25\% alumina/ $50 \%$ mullite-50\% alumina/ $25 \%$ mullite- $75 \%$ aluminal alumina, was deposited on silicon carbide and survived thermal treatments with no observable cracking or spalling [82]. This type of coating protects silicon carbide material up to $1100^{\circ} \mathrm{C}$ for long-term applications.

\section{6-Protection with the use of an inert gas}

Recently a new concept has been developed. It is proposed that the introduction of an inert gas into the boundary layer at the carbon composite surface will provide some protection. Some authors [83] have studied the $\mathrm{C} / \mathrm{C}$ oxidation in the presence or absence of protection provided by an inert nitrogen introduced into the wall surface boundary layer (figure 10). They have shown that the carbon mass loss at the tube surface is reduced, by a factor of about 3.3 at $1500 \mathrm{~K}$ and by a factor 3 at $2000 \mathrm{~K}$, by the nitrogen gas protective boundary layer flow. This promising new protective concept must be optimized according to other flow conditions, temperatures and pressures.

\section{7-Conclusion}

At present, many advanced oxidation protection systems have been developed but there is no universal solution for the general problem of protecting $\mathrm{C} / \mathrm{C}$ against oxidation. The main developed approach is the use of an external diffusion barrier. However, due to the thermal expansion mismatch between coating and substrate, oxidation protection must also include glass formers in the matrix, coatings on fibers, transition layers, oxygen barrier layer (carbide or nitride), outer glass sealant. The protective coatings become more and more elaborated with the use of graded mixed layers. The main components used are based on silicon and boron. With siliceous coatings, oxidation protection is efficient up to $1800^{\circ} \mathrm{C}$ in a dry atmosphere ( 1 bar) for medium-term applications. At higher temperatures or lower pressures, this system fails due to the active oxidation phenomenon. Boron compounds are good glass formers and used as outer glass sealants but they are too moisture sensitive, which reduces the oxidation protection to medium-term applications up to $1100^{\circ} \mathrm{C}$.

Thereby, there is a need for oxidation protection systems which are not moisture sensitive and which can work above $1800^{\circ} \mathrm{C}$ for long-term applications. It is possible that protection by an inert gas could be developed with this objective in mind.

[1] J.D.Buckley., Ceramic Bulletin 67 (2) (1988) 364.

[2] J.X.Zhao., Carbon 23 (1) (1985) 9.

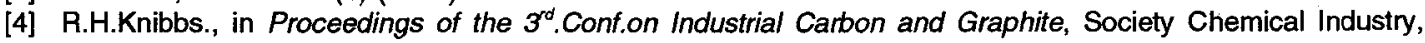
London, (1971) p 297.

[5] P.A.Thrower., Carbon 20 (6) (1982) 457.

[6] J.L.Wood., Carbon 19 (1) (1981) 61.

[7] J.X.Zhao., in Abstracts 15 th Conf. on Carbon (1981) p 522.

[8] E.Fitzer., J.Chim.Phys. 81 (11/12) (1984) 717.

[9] K.L.Luthra., Carbon, 26 (2)(1988) 217.

[10] S.T.Dimitrijevic., in Proceedings of the $20^{\text {th }}$ Biennal Conf on Carbon, Santa Barbara CA, (1991).

[11] L.H.Keys., in Proceedings of the Symposium on Properties of High Temperature Alloys (The Electrochemical Society), Princeton, 77 (1) (1977).

[12] E.A.Gulbransen., J.Electrochem.Soc. 113-1 (1-6) (1966) 1311.

[13] W.Hinze., J.Electrochem.Soc. 123 (7) (1976) 1066.

[14] T.Narushima., in Proceedings of the International Meeting on Advanced Materials, vol 4, Pittsburgh (1989).

[15] G.H.Schiroky., GA-A18696 (1986).

[16] S.C.Shingal., in Proceedings of the Symposium on Properties of High Temperatures Alloys with Emphasis on Environmental Effects (edited by Z.A.Faroulis), 77-1 (1976).

[17] R.C.Dickinson., in Proceedings of the Oxidation Resistant C/C Composites for Hypersonic Vehicles Application, Workshop, Hampton, VA, NASA conference publication 2501 (1987).

[18] D.E.Rosner., J.Phys.Chem. 74 (9) (1970) 1829.

[19] E.Sheehan., J.Am.Ceram.Soc. 65 (7) (1982) C-111.

[20] H.Du., Ph.D.thesis. Pennsylvania State University, PA (1988).

[21] W.C.Tripp., J.Am.Ceram.Soc. 59 (9-10) (1976) 399.

[22] W.L.Vaughn., J.Am.Ceram.Soc. 73 (6) (1990) 1540.

[23] A.H.Heuer., J.Am.Ceram.Soc. 73 (10) (1990) 2785.

[24] J.E.Sheehan., Carbon 27 (5) (1989) 709. 
[25] Y.Grenié., Aérospatiale, NT $n^{\circ} 89 / 88$ AQEM/R (1989).

[26] J.R.Striffe., Ceram. Bull. 67 (2) (1988) 369.

[27] M.P.Bacos., $4^{\text {th }}$ International Symp, sur "les matériaux utilisés en ambiance spatiale", Toulouse (1988).

[28] S.M.Sim., in Symposium on Better Ceramics through Chemistry, Palo Alto USA (1986).

[29] S.M.Sim ., in "Ultrastructure processing of advanced ceramics", Gainesville Florida, USA (1983) p 995.

[30] W.J.Lackey., Ceram. Eng. Sci. Proc. 9 [9-10] (1988) 1223.

[31] J.Chown., in Specials Ceramics (edited by Popper) (1962).

[32] J.R.Dentzer., SAMPE Quartely 2 (3) (1971).

[33] D.W.Mc Kee., in Fundamental Issues in Control of Carbon Gasification Reactivity (edited by J. Lahaye et P. Ehrburger), NATA ASI Series E, 192 (1991) p 485.

[34] J.M.Criscione, ML-TDR-64-173, Part II (1974).

[35] H.Jehn., J. less-Common.Metals 100 (1984) 321.

[36] D.B. Fischbach., in Proceedings of the $20^{\text {h }}$ Biennal Conf. on Carbon, Santa Barbara CA (1991) p 412.

[37] D.W.Mc Kee., Carbon 24 (6) (1986) 737.

[38] J.L.Kaee., AFOSR-TR-88-0284 (1988).

[39] M.Inagaki., Carbon 29 (3) (1991) 287.

[40] C.E.Chang., Mat.Res.Bull 6 (1971) 1287.

[41] E.G.Fatzer., US Patent, 3,925,577 (1975).

[42] J.V.Milewski., US Patent, 2,528,823 (1983).

[43] F.S.Galasso., US Patent, 4,425,407 (1984).

[44] R.D.Veltri., US Patent, 4,476,178 (1984).

[45] J.W.Patten., US Patent, 4,500,602 (1985).

[46] C.W.Stroud., NASA TM 81799 (1980).

[47] G. Rousseau., Brevet Européen 0.282.386 A1 (1988).

[48] J.Cullinan., AFOSR-86-0251 (1990).

[49] D.C.Rogers., in Proceedings of the $7^{\text {th }}$ National Sampe Technical Conference, Albuquerque, vol 7 (1975).

[50] A.H.Klepping., AlAA-86-1499 (1986).

[51] T.Kinjo., Kawasaki steel techn report 23 (1990) 54.

[52] W.Kowbel., in Proceedings of the Third Int. Symp. on Ceramic Materials and Components for Enginer, Las Vegas (1988).

[53] I.Jawed., Mat.Res.Bull. 21 (1986) 1391.

[54] D.W.Mc Kee., Carbon 26 (5) (1988) 659.

[55] D.W.Mc Kee., Carbon 24 (3) (1986) 331.

[56] R.C.Shaffer., US Patent 4,321,298 (1982).

[57] Vasilos., US Patent, 4,426,600 (1982).

[58] S.Ragan., in Proceedings of the $20^{\text {th }}$ Biennal Conf on Carbon, Santa Barbara CA (1991) p 428.

[59] V.S.Kilin., Moscow. translated. from. Poroshkovaya. Metallurgica 2 (146) (1975) 44.

[60] H.Vincent., in Third European Conference on Composite Materials, Bordeaux, (1989) p 257.

[61] Y.Deslandes., J.Mater.Sci.Lett. 9 (1990) 200.

[62] D.A.Eitman., in Gas Turbine and Aeroengine Congress and Exposition, Toronto (1989).

[63] D.M.Barret., in Proceedings of the ASC Symposium on High Temperature Composites, Dayton, (1989) p 282.

[64] W.J.Lackey., in Proceedings of the $10^{\text {th }}$ International Conference on Chemical Vapor Deposition, 1987, p 1008.

[65] T. Hirai., in Proceedings of the $19^{\text {th }}$ Univ. Conf. on Ceramic Science, 1982, p 329.

[66] T.Hirai., J.Mater.Sci., 17, 1982, 1320-1328.

[67] T.Hirai., in Proceedings of the $8^{\text {th }}$ International Conference on Chemical Vapor Deposition, 1981, p 790.

[68] K.Hiraga., J. Am. Ceram. Soc. 66 (8) (1983) 539.

[69] T.Hirai., in Proceedings of the $19^{\text {th }}$ Univ. Conf. on Ceramic Science, 1982, p 347.

[70] D.P.Stinton., Ceram Eng. Sci. Proc. 5(7-8) (1984) 668.

[71] M.Touanen., Materials Science and Engineering. A147 (1991) 239.

[72] W.Y.Lee., J. Am. Ceram. Soc. 74 (9) (1991) 2136.

[73] W.Y.Lee., J. Am. Ceram. Soc. 74 (10) (1991) 2649.

[74] K.Bartsch., J.Mater.Sci. 26 (1991) 4318.

[75] S.Zirinsky., J.Electrochem.Soc.: Solid-state Science and Technology 125(2) (1978) 305.

[76] D.P.Stinton., Ceram.Eng.Sci.Proc. 6(7-8) (1985) 707.

[77] B.Bavarian., in Proceedings of the 35th International Sampe Symposium, book 2 (1990) p 1348.

[78] E.Lugscheider., High Temp.High Pressures 21 (1990) 119.

[79] Y-L Jeng., Scripta Metallurgica et Materiala 28 (1993) 453.

[80] S.M.Sim, in Ultrastructure Proceessing of Advanced Ceramics, edited by J.D.Mackenzie and D.R.Ulrich, p 995. 
[81] D.W.McKee., Carbon 25 (4) (1987) 551.

[82] M.V.Roode., Ceram.Eng.Sci.Proc. 9 (9-10) (1988) 1245.

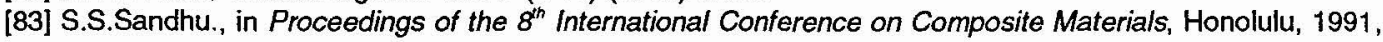
p. 22-F-1.

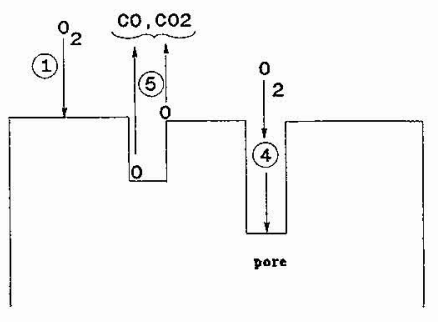

unprotected carbon-carbon composite

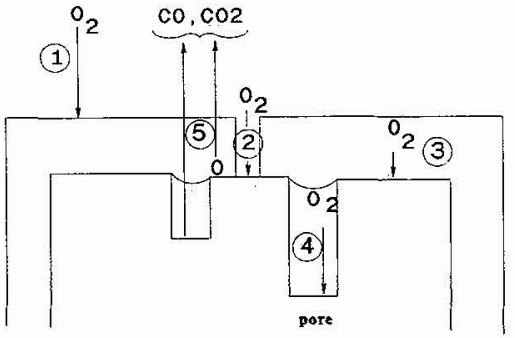

protected carbon-carbon composite

(1) Gas phase diffusion (across boundary layer)

(2) Gas diffusion through cracks in the coating

(3) Condensed phase diffusion

(4) Gas diffusion through cracks in the composite

(5) Reaction

Figure 1 : Schematic representation of limiting steps during oxidation

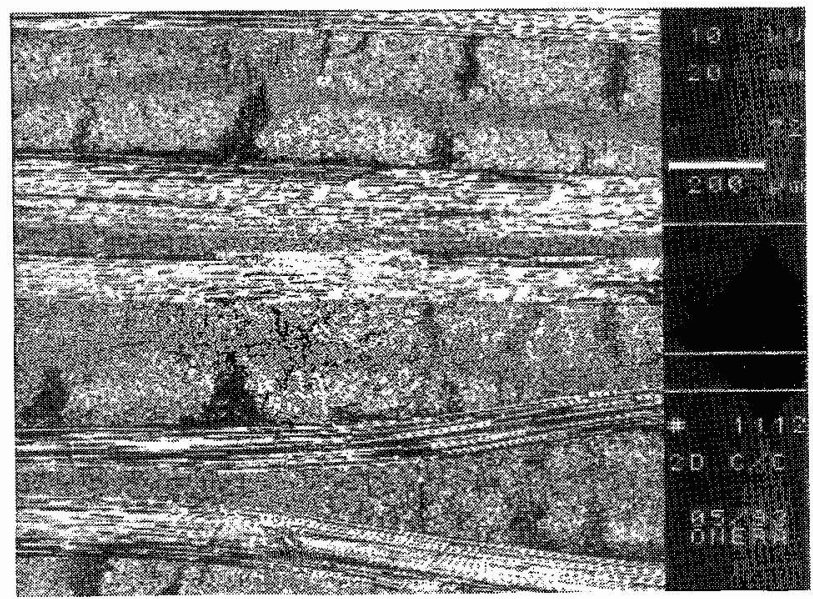

Figure 2 : SEM photograph of a $2 \mathrm{D} \mathrm{C/C}$ 


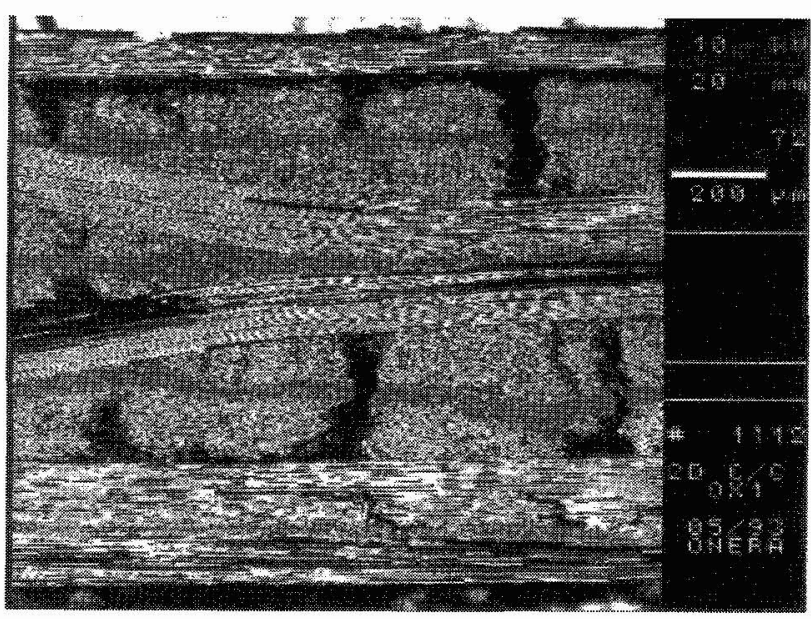

Figure 3 : SEM photograh of an oxidized $2 \mathrm{D} \mathrm{C}$ (low temperature)

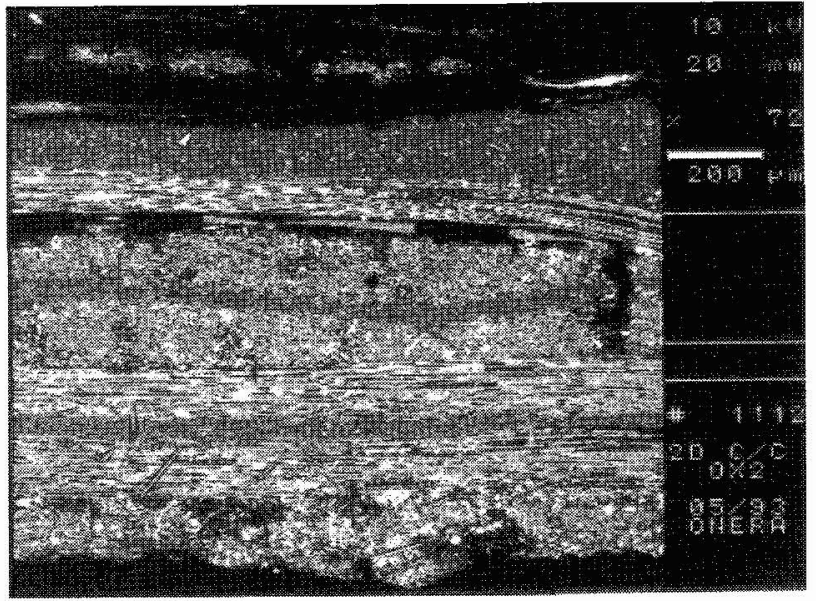

Figure 4 : SEM photograph of an oxidized $2 \mathrm{D} \mathrm{C/C}$ (high temperature)

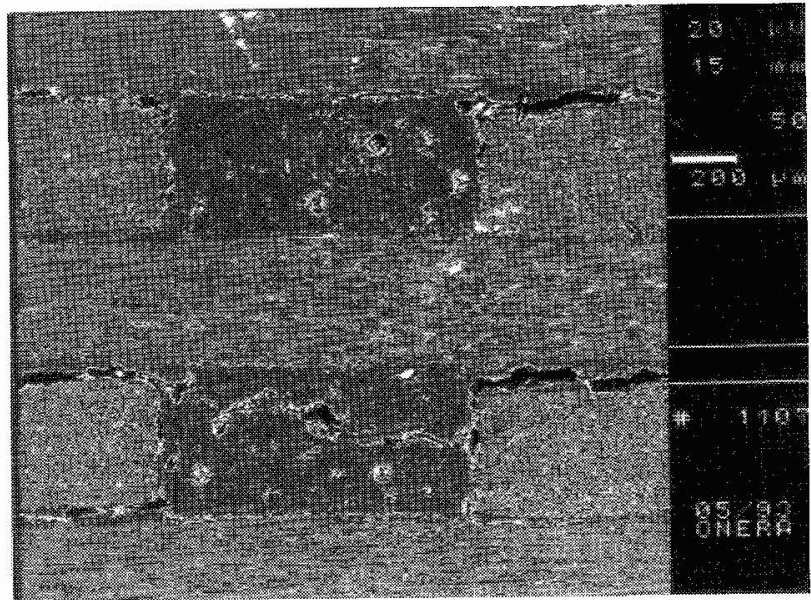

Figure 5 : SEM photograph of a $3 \mathrm{D}$ C/C 


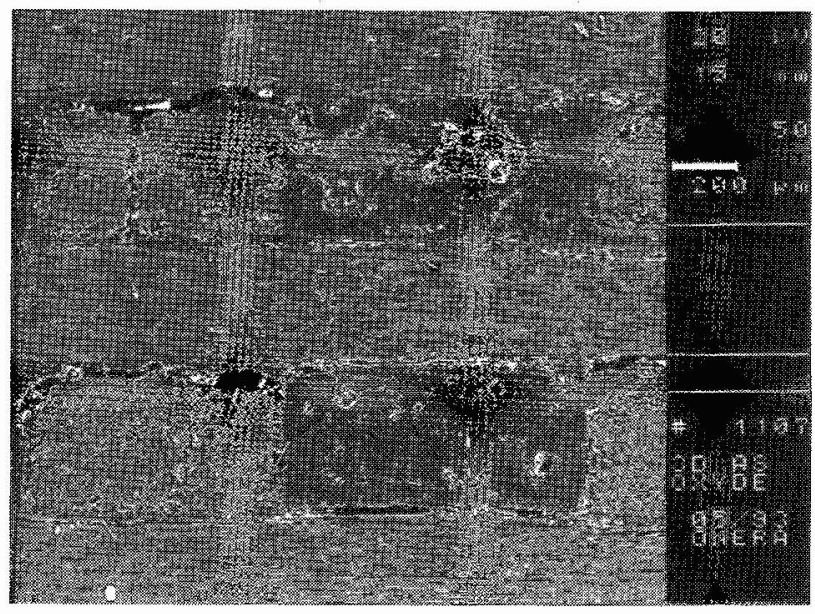

Figure 6 : SEM photograph of an oxidized 3 D C/C

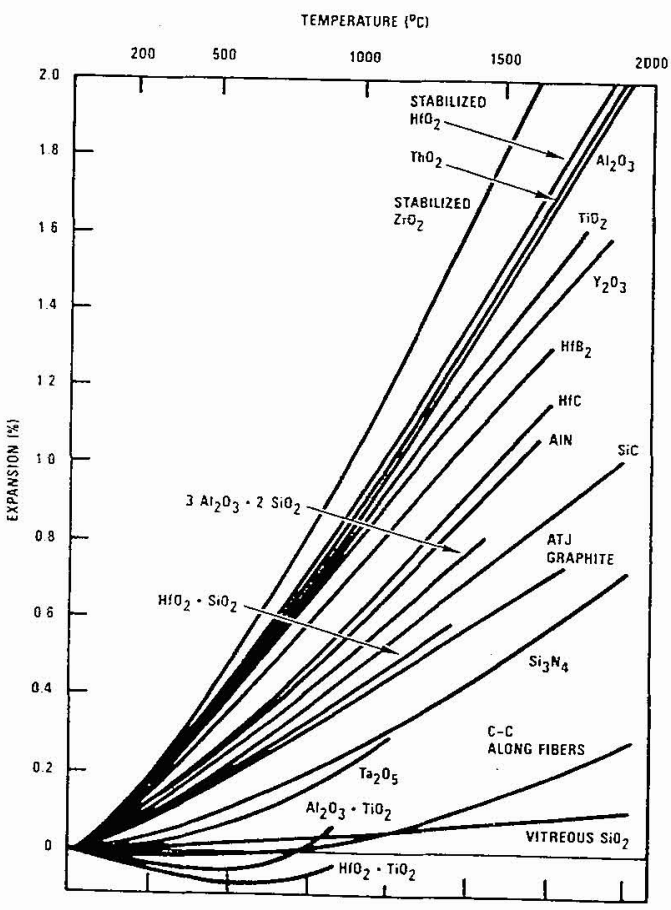

Figure 7 : Thermal expansion coefficients of refractory materials 